\title{
The Impact of Street Layout Design on Non-Motorized Activities with Nairobi City, Kenya
}

\author{
Mwangi Josephine ${ }^{1 *}$, Gariy Abiero1,2, Makworo Micah1 \\ ${ }^{1}$ Centre of Urban Studies, Jomo Kenyatta University of Agriculture and Technology, Nairobi, Kenya \\ ${ }^{2}$ School of Civil Engineering, Jomo Kenyatta University of Agriculture and Technology, Nairobi, Kenya \\ Email: *Josephine.mwangi@jkuat.ac.ke
}

How to cite this paper: Josephine, M., Abiero, G., \& Micah, M. (2021). The Impact of Street Layout Design on Non-Motorized Activities with Nairobi City, Kenya. Current Urban Studies, 9, 252-278. https://doi.org/10.4236/cus.2021.92017

Received: April 12, 2021

Accepted: June 15, 2021

Published: June 18, 2021

Copyright (c) 2021 by author(s) and Scientific Research Publishing Inc. This work is licensed under the Creative Commons Attribution-NonCommercial International License (CC BY-NC 4.0). http://creativecommons.org/licenses/by-nc/4.0/ cc) (i) (8) Open Access

\begin{abstract}
The design of street layouts in urban areas in developing countries has been centered around motorized transportation with little close to no consideration to non-motorized modes of transport. This has resulted in increased congestion, poor urban air quality, reduced safety for pedestrians and cyclists and poor health of urban residents. The transport planning of street layouts, especially within Nairobi City, has not adequately taken care of non-motorized transport (NMT) such as walking and cycling and the activities that occur around them resulting in competing use of pavements and roads, exposing pedestrians, cyclists, handcart operators and street vendors to insecurity and harassment. Through observation and interview methods, this study examined the current condition of the street layout along Luthuli and Haile Selassie Avenues and documented the NMT activities occurring along the two streets. The study aimed at assessing the impact street layout has on non-motorized transportation activities in order to determine both the positive and negative aspects of urban street design, in an attempt to improve the built environment of identified streets and in any other forthcoming redevelopments. It emerged that physical form and qualities of a place shape the way it is used, and the way people and vehicles move through it. Therefore, this study recommended that urban street design should help create spaces that connect with each other sustainably providing the right conditions to encourage walking, cycling and use of public transport.
\end{abstract}

\section{Keywords}

Street, Layout Design, Non-Motorized Transportation, Motorized Transportation, Impact 


\section{Introduction}

\subsection{Background to Study}

Modern transport is an essential ingredient for development, allowing the movement of labour, supplies and goods, and enabling citizens to access key resources and services (Haq \& Schwela, 2013). The United Nations (UN) recognises mobility as a key driver of economic and social development determining access to jobs, goods and services (UN-Habitat, 2010). Non-motorized transport offers basic mobility, affordable transport, and access to public transport and health benefits. Improving the convenience, comfort and safety of walking and cycling reduces the demand for travel by personal motor vehicles, helping to alleviate the critical traffic challenges facing many cities (UNEP, 2009). As zero-emission modes, walking and cycling are critical efforts in reducing the harmful local pollution and greenhouse gas emissions.

In most developed countries, there has been a positive change towards provision of non-motorised transportation infrastructure within the overall street layout in a bid to promote walking and cycling within urban spaces (Victoria Transport Policy Institute, 2019). This has seen a reduction in transport congestion and air pollution as well as improved health among the urban populace. In cities like Amsterdam and Copenhagen, walking and cycling are the preferred modes of transport and are given the right of way. This is mainly because they have adequately invested in non-motorised transport (NMT) infrastructure and it is not only safe but convenient to walk or cycle.

In urban areas of developing countries, where high rates of urban growth, large poor populations, and high densities prevail, walking is the only option available to a significant portion of the population. In African cities, 30 to 35 percent of all trips are by walking but in some cities, like Dakar and Douala, the share is much higher, over 60 percent (Montgomery \& Roberts, 2008). However, infrastructure for pedestrians and cyclists is often inadequate in developing countries. In general, the poorer and smaller the city, the more important NMT becomes, capturing as many as 90 percent of total person trips. In densely packed urban cores, NMT provides access to places that motorized modes cannot reach and are often the fastest means of getting around (Cervero, 2013). Yet these non-motorized modes of transport are not always adequately recognized, and city planners very often tend to disregard the needs of pedestrians and cyclists when designing street layouts (Hook, 2005).

In Kenya, NMT is an important mode of travel especially for the urban poor and low-income groups in many urban centres. The United National Environmental Programme (UNEP) (2009) estimates that $47 \%$ of the urban population use walking as its mode of transport while cycling and transit cater for $1.2 \%$ and $33 \%$ respectively. At the same time, access to the city is becoming more and more expensive and complicated because of the increased distances involved and the inadequate nature of the transport system in relation to the travel needs and 
financial resources of urban dwellers, particularly the most disadvantaged (Diaz Olvera et al., 2008; Vasconcellos, 2001). Apart from the day-to-day difficulties that are created by inadequate transport supply, a number of studies on the links between poverty and transport show that factors that impede mobility also limit access to the resources which are necessary to escape from poverty (Bryceson et al., 2003; Lucas, 2011; Salon \& Gulyani, 2010; Sitrass, 2004a, 2004b).

In most Kenyan cities, with Nairobi leading, various means of transport compete for the same road space including buses, matatus, private cars, rickshaws (tuk tuk), motorcycle taxis (boda boda), bicycles, pedestrians, hand carts among others as shown in Figure 1 below. The high rate of urbanization coupled with the competition of the same road space by various modes of transport has raised the demand for non-motorised transportation infrastructure which has not been met adequately hence the traffic jams in most urban areas with the worst traffic congestion being experienced in Nairobi (Ndatho, 2018).

Despite the significance of NMT as a potential alternative mode of travel for the bulk of the population in Nairobi, the general design of the major road links/arterials in Nairobi discourages the use of walking and bicycle as alternative modes of travel. Majority of road infrastructure investments in Nairobi City and County at large are channelled towards building roads to facilitate efficient movement of vehicles as opposed to movement of most road users who in this case are pedestrians and cyclists. There is insufficient and inefficient emphasis on people as opposed to vehicular traffic when designing the street layouts of various roads within the busy Nairobi Central Business District (CBD), especially along with Luthuli and Haile Selassie Avenues as shown in Figure 2. Poor maintenance to ensure safety and comfort in use along streets by NMT users, as shown in Figure 3 below, in Nairobi has continued to deteriorate despite the growing populations and increased motorized movement along the same streets. This has led to increased congestion, poor safety of NMT users, poor air quality for all road users and increased travel times.

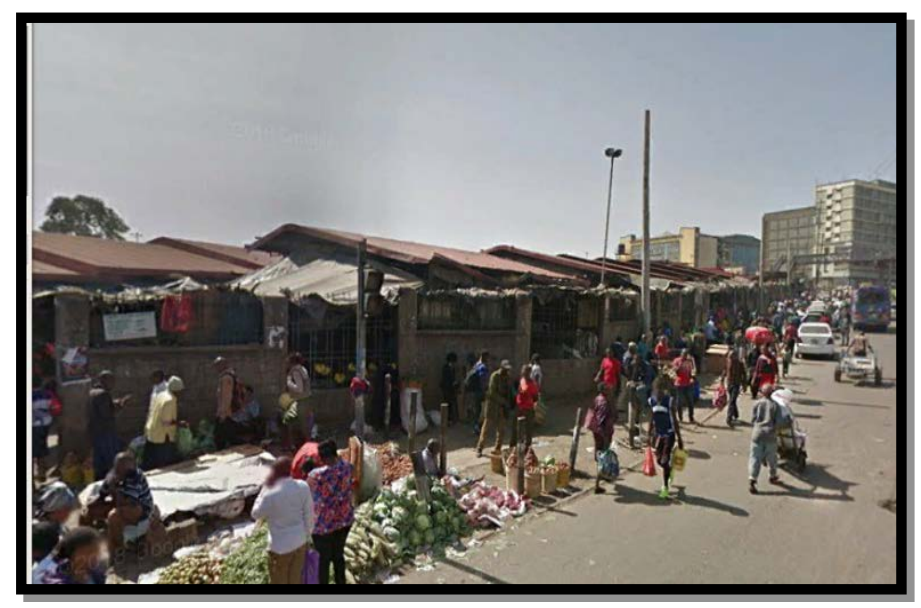

Figure 1. Pedestrian walkways along a section of Haile Selassie Avenue encroached upon by vendors outside Muthurwa market. Source: Author 2019. 


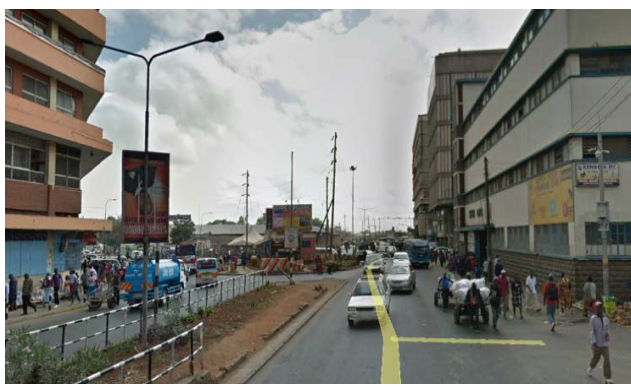

Figure 2. Insufficient NMT infrastructure resulting into NMT users pouring onto road carriage ways. Source: Author, 2019. December, 2020.

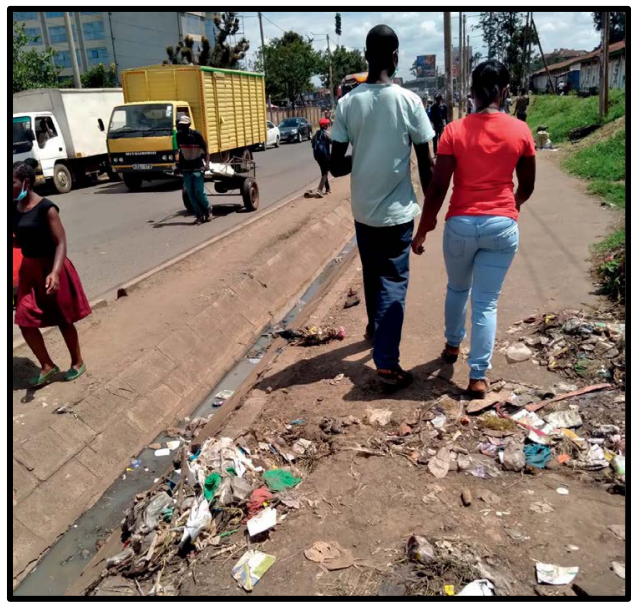

Figure 3. Open drainage and garbage strewn on footpath, Landhies Road. Source: Climate and Development Knowledge Network, February 2021.

There is an urgent need to redesign streets layouts with not just mobility in mind, but also access within the overall urban form and structure. This involves planning and designing for a suitable urban environment that takes into consideration the relationship that exists between blocks, streets, buildings, open spaces, and landscape which make up urban areas. It is the interrelationship between all these elements, rather than their characteristics that bond together to make a place accessible.

\subsection{Objective of the Study}

The overall objective of the study was to investigate the impact the layout of streets on non-motorized transport activities in Nairobi City's Central Business District (CBD).

The study ought to examine the street layout of and assess non-motorized transport activities within Luthuli and Haile Selassie Avenues in Nairobi City's Central Business District (CBD). This was aimed at establishing the impact of street layout on non-motorized transport activities within Luthuli and Haile Selassie Avenues in Nairobi City's Central Business District (CBD). The results 
would help come up with proposed layout redesigns of identified streets for optimal functioning of non-motorized transportation activities within Luthuli and Haile Selassie Avenues in Nairobi City.

\subsection{Justification and Significance of the Study}

This study was timely in proposing insights into sustainable streets that cater to all road users and reduce congestion, pollution, and accidents in road use. This would help in the development of people-centered design of streets to cater to all road users.

In addition to the prevailing global public health pandemic from the coronavirus disease of 2019 (COVID-19), the results of this study would provide some insights and information on how to design streets that are responsive to changing environments in specific the prevailing public health pandemic. As the COVID-19 outbreak disrupts mobility worldwide, more and more cities are transforming their streets to increase space for walking and cycling and reduce car use during and after the pandemic. These changes are designed to help people get around while maintaining social distancing, but they can also help cities transition to a more resilient, more connected, lower carbon future.

Through this study, the relevant authorities within the Nairobi City County Government (NCCG) and the newly established Nairobi Metropolitan Services (NMS) would become aware of the impact street layouts have on non-motorized transport modes. This would help the agencies provide transportation solutions that are user friendly, effective and efficient in alleviating current urban accessibility challenges the city of Nairobi is currently facing.

The results of this study were valuable in understanding urban form and structure with regards to street layouts and how they affect various non-motorised transportation activities along their spaces. This would help designers, planners and users understand that streets need to be designed not as individual elements but as part of a collective involving building, open spaces and the general landscape.

Moreover this study would benefit both the users as well as business owners along the identified streets within the study area as their input impacted the findings and recommendations in the study. These would help inform urban planners and designers of the needs of the user in a bid to reshape the way the city could be designed in the coming future.

\subsection{Limitations of the Study}

Geographically, the study was limited to the two streets, Luthuli and Haile Selassie Avenues, both located within the Nairobi Central Business District (CBD) area. Theoretically the study concentrated on quality of contemporary urban design with regards movement of people, goods and services, and how it affected the urban environment, as examined by various theorists and practitioners. Therefore, a review of urban design principles that have evolved over time as the 
result of different contributions of various theorists and practitioners was reviewed. The study employed a qualitative research approach through a case study analysis of selected streets. Observation and interviews were used as the primary data collection methods Causal analysis will be employed to study how the independent variable (layout of streets) affected changes in the dependent variable (non-motorized transportation activities).

Due to the prevailing public health crisis caused by the Covid-19 pandemic, target populations within study area were affected which heavily impacted on the data collection methods as well as sample sizes and methods in designated areas.

\subsection{Organization of Study}

This research was organized into five main chapters:

Introduction which gave the background to the theme of the study and further explained the problems the study aimed to address through statement of identified problem, objectives, significance, and justification.

Review of literature-critical analysis of theories on streets as public spaces and the impact the layout of non-motorized transportation infrastructure has on uses or streets as public spaces.

Data collection \& analysis of results and describes the methodology that was applied in carrying out the research study and

Case study presented a summary of the research study results, analyzed data.

Summary, Conclusion and recommendation-Presentation of study findings which inform the given recommendations.

\section{Literature Review}

\subsection{Urban Form, Structure and Street Layouts}

\subsubsection{Urban Form}

The transport network is said to act as a base for the development of urban areas. While it affects our cities' growth in quite prominent ways, it also influences its users. The core purpose of road remains the same, movement (Postaria, 2017). People make journeys to reach destinations, and the base network offers them options to reach those places. Moreover, the options provided may vary based on the mode of transport (private car, public transport, or nonmotorized transport). Since walking is considered an integral part of a journey, it often exhibits diversity with respect to the purpose of the journey as well as the user. The diversity is observed in terms of the choices (often varying according to different groups of users). Similarly, cycling has its own prerequisites for its users, and affects people's choice of mode. The variations in the urban context such as network, environment, connectivity, and the indirect relation to other people play an important role in the decision-making process in the choosing of different modes of transport.

In their study of urban form and travel outcomes in Mexico's largest cities, 
Montejano et al. (2019) found that various measures, such as compactness, spatial configurations and street networks of an urban form are consistently and often strongly related to transportation outcomes.

Similarly, in their report on how land use and transportation systems impact public health, Frank and Engelke (2001) found that the built environment can influence physical activity patterns through an analysis of transportation systems and land development patterns which constitute the urban form. Transportation systems were broken down into network of streets in a city, the design of individual streets and highways, transit systems, and separated systems for non-motorized users. Land development patterns included residential and commercial density and the mixture of uses over a given area, as well as the design of buildings and sites.

Across cities, neighbourhoods, and individuals, the built environment influences how, where, and how much people travel. This shows the impact various design elements along a street and the spaces that bind it have on travel activities within it.

\subsubsection{Street Networks}

Settlements are made of people. Humans require many things to survive in the world, such as water, energy, information, etc., which flow back and forth between people through mutual networks. However, movement of people is also particularly important. This movement often occurs through the transportation network, the most visible of all networks. Being evident on plans, the road networks tend to create a picture of our cities. Beginning with a number of roads and their total length, followed by their arrangement and spatial expansion from the city core, and at last the structures they form, all features give us a reflection of the transport network in the city, which, when schematically studied, can be distinguished in terms of the patterns formed (Postaria, 2017).

Street networks influence trip route and mode choice through the ways in which trip origins and destinations are connected. Networks can be rated as either high in connectivity, where there are a large number of blocks and intersections per some unit of area, or low in connectivity, where there are fewer blocks and intersections over the same area (Frank \& Engelke, 2001). The grid pattern is the archetype of the high connectivity network. The gridiron is a simple system of two sets of parallel streets crossing at right angles to form square or rectangular blocks. Streets are non-hierarchical, that is, there is less differentiation of streets by traffic volume. Grids are theoretically capable of increasing walking and biking trips in two ways. Grids have a large number of intersecting streets, thereby reducing the distance between trip origin and destination. Grid patterns also provide for a large number of alternative trip routes, allowing pedestrians and bicyclists to vary their routes for variety, safety, and convenience.

In contrast to grids, hierarchical, curvilinear street networks are lower in connectivity. In these types of systems, which have a number of variations, streets are curvilinear, often following landscape contours. Streets are deliberately or- 
dered into a hierarchy. Residential streets often loop back upon themselves or are cul-de-sacs. Residential streets feed into major arterial roads, which are designed for heavy traffic volumes and often feature no pedestrian or bicycle amenities. These networks are characterized by a low number of blocks and intersections per unit of area. Theoretically, they discourage walking and biking by increasing trip length and decreasing both route and modal choice (Southworth \& Owens, 1993; Frank et al., 1999). In between the purest grid pattern and the most disconnected, hierarchical pattern there are a large number of variations. Figure 4 graphically illustrates the major differences between systems that are high and low in connectivity.

The original unplanned street networks have evolved and shall keep on evolving over time. The street network, quite simply, can be described as interconnecting lines and points, which, in urban planning terms, are referred to as "links and nodes". The overall structure formed represents the street layout which acts like the skeleton of the city plan. Every city, by default, has a different street layout; some influenced by physical barriers, some by topography and some others by the mere expansion of the city. However, many of them may have followed a similar process of transformation from ancient times to the modern era. When analysed, it may be observed that most street networks do not have a unique growth trend. Indeed, a small part of the street layout structure is repeated several times, in different manners to form a larger network. That particular aspect, which appears on several different networks, is defined as the street pattern.

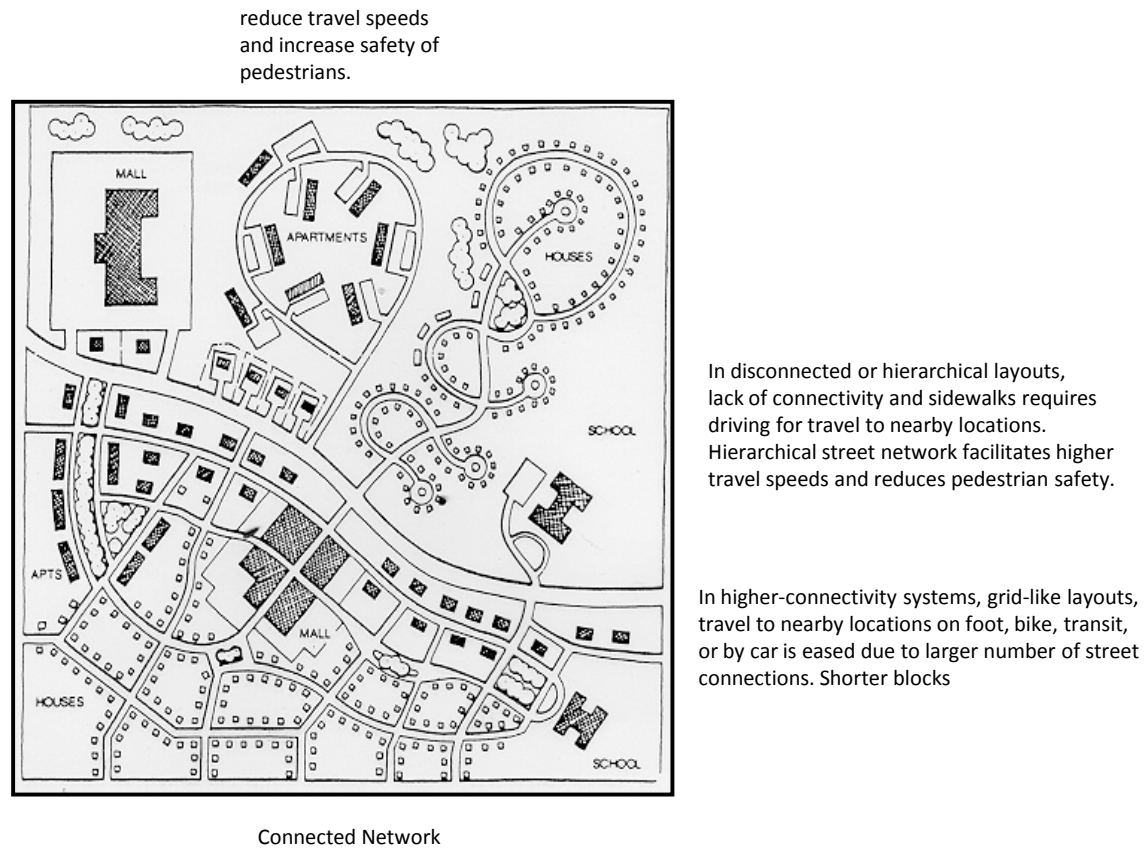

Figure 4. Forms of street network configuration. Source: Drawing by Duany Plater Zyberk as shown in Spielberg F. The traditional neighborhood development: how will traffic engineers respond? ITE J. 1989; 59:17. 


\subsubsection{Street Layout}

Streets embody the most basic element of a city's spatial structure. From ancient times, the street has played an indispensable role in cities by creating space for mobility, communication, commerce, and social interaction (UN-Habitat, 2013). Street design impacts route quality for different modes. Streets can have amenities such as shade trees, sidewalks, crosswalks, and bike paths, for example, which will make walking and biking more attractive. Streets can simultaneously discourage driving using traffic calming measures that are deliberately designed to slow vehicle speeds and hinder vehicle movement.

As with street networks, certain types of street layouts will encourage walking and biking, while others will discourage it. Some neighbourhood streets are characterized by the provision of sidewalks, bike lanes, and other amenities. Streets that particularly encourage walking and biking have features that calm traffic, usually by providing barriers to motorized vehicles in order to reduce speeds.

Christopher Alexander, in The Pattern Language, stated, "each pattern is a three-part rule, which expresses a relation between a certain context, a problem, and a solution". When described in relation to street patterns, the statement reflects the three central aspects of transportation planning. The context is the building frontage which defines the character of the street; the problem reflects the issues of connectivity and accessibility which is the actual purpose of the street network; and the solution lies in understanding the relation of such street features (as connectivity, accessibility, etc.) to the street pattern itself (Alexander et al., 1977).

Therefore modes, arteriality, access constraint and connection type together create a system for transport network management while frontage use helps in creating a street type which together with above four aspects creates a system for generating a street layout (Postaria, 2017).

\subsection{Non-Motorized Transportation in Urban Areas}

Non-Motorised Transport (NMT), also called active transport and human powered transport, refers to walking cycling, and variants such as wheelchair, scooter, and handcart use. NMT plays an important and unique role in an efficient transport system (Litman, 2012). It provides basic mobility, affordable transport, access to motorised modes, physical fitness, and enjoyment. Litman (2012) identifies a long list of benefits, including user gains, infrastructure improvements and the reduction of negative environmental impacts. In medium-sized cities in Japan, Germany, and the Netherlands, $40 \%$ to $60 \%$ of all trips are made by walking and cycling, while in similarly sized cities in India this share is as high as $80 \%$ (Heierli, 1993).

NMT in Africa is not driven by the type of benefits that have been identified by Litman (2012). In Africa NMT is a necessity. A large majority of urban residents in Sub-Saharan Africa (SSA) are from low-income households. The urban poor are dependent on NMT and their urban transport expenditures account for $10 \%$ (in the smaller cities) to $20 \%$ of their household incomes (Sub-Saharan 
Africa Transport Policy Program [SSATP], 2005).

Lewis Mumford once said, "no city can solve its transportation problem if it neglects the greatest, self-propelled vehicle of all: The Pedestrian" (Mumford, 1981). This statement can be related to our cities' present condition. While we all know, non-motorized travel is one of the most used, it is often not seen to be as important as it is. If we look at it the other way, it can be considered that the level of variety a street offers attracts different people, which then creates the mingling complex. Starting from the number of blocks, intersections, and access points until the very end of loops or cul-de-sacs, each element defines the route options differently, thus influencing the travel pattern (Postaria, 2017).

The promotion of non-motorised travel modes is one key element for mitigating the social and environmental effects of motorised traffic (Koska \& Rudolph, 2016; Winters et al., 2017). Frequently, the design of the built environment is considered as an important factor for that endeavour (Næss, 2015).

\subsection{Relationship between Street Layout and Non-Motorized Transportation in Cities}

Many cities and communities lack sufficient, safe infrastructure for walking and biking such as protected bike lanes, sidewalks, walkways, or pedestrian bridges. These barriers relate to underlying issues with urban design and planning (Martin et al., 2014). Private-vehicle-oriented transport and spatial planning have been business as usual in most countries (Servaas, 2000). Lack of accessible, convenient public transportation also serves as a barrier to non-motorized transportation if an individual cannot walk or bike to a transit station and instead must drive to reach destinations. Long-term, integrated vision and planning for non-motorized transportation in communities is often inadequate or completely absent.

Where street layouts have been designed with the Non-Motorised Transport (NMT) users in mind, there has been improved accessibility, reduced congestion, reduced road fatalities, improved air quality and reduced carbon emissions. In addition, NMT decreases household transportation costs and promotes public health (Herrman 2015). Adding social benefits to this list, walking, and cycling collectively build community, promote health, and minimize the environmental impact of transportation.

Streets infrastructures need to be designed so that people can walk and cycle safely and access destinations of daily importance (Cervero \& Kockelman, 1997; Ewing \& Cervero, 2010). Expanded sidewalks, improved crosswalks, and protected bike lanes are some of the many ways to create this safer space for non-motorized transport. Traffic calming, streetscape improvements, traffic speed reductions, vehicle restrictions, congestion pricing, and road space reallocation are other supportive conditions that provide safe space for walking and cycling (Litman, 2010, 2012). In walkable communities, places of daily importance are within walking distance; public transportation is nearby, efficient, and comfortable; and walkways and paths have pleasant surroundings replete with natural elements (Biggar 
\& Ardoin, 2017; Ross et al., 2017). These elements enable and motivate individuals to walk and cycle.

Urban environments can be designed and managed in ways that support sustainable transportation (Cervero \& Duncan, 2003; Deyoung, 1985; Ewing \& Cervero, 2010). To support growth in the mode share of walking and cycling, cities' and communities' street layouts need to be organized in such a way as to prioritize these modes and limit the space available to moving and parked automobiles.

\subsection{Literature Review Summary and Research Gap}

Most of the presented urban design theories aimed at creating a live able and vibrant public place which was cognizant of the culture of the day. There is a positive social consequence to knowing about the connection between the designed layout of streets and use of the streets. Design theories describe successful design characteristics but lack an adequate explanation on why and the way these physical forms enhance use. When the design concerns public streets, there are several problems. The user in the public street is unknown because, although we can know about cultural norms, users change with time and so do functions of the street, and the regulations that govern the use of the street environment. However, there are numerous examples of urban forms that survived these changes and are still able to accommodate the myriad uses they have been put to. What is the secret of those places? Maybe their configuration is such that it renders them adaptable. Maybe it is solely due to circumstances beyond the street environment. Further research should be conducted to assess the impacts of specific street-scale interventions on walking, biking, and related activities.

\section{Methodology}

The study employed descriptive qualitative approach to research as it is a function of researcher's insights and impressions on how street layouts impact non-motorized transportation activities within Nairobi City's CBD.

A case study research design, a form of qualitative study, was adopted to collect and analyse data on of street layouts and non-motorised transportation activities along Luthuli and Haile Selassie Avenues in Nairobi City's CBD. Efforts were made to study the independent variable (street layouts) and the dependent variable (NMT activities) within the broad areas of study (urban street design) and geographical area of study (selected streets within Nairobi City's CBD).

Observation and interview were used to collect primary data whereas archive method was employed to collect secondary data. Under the observation method, the information was sought by way of direct observation of the environmental conditions and physical traces along Luthuli and Haile Selassie Avenues in Nairobi city's CBD.

The interview method through personal interviews and, where possible, through telephone interviews was be used to collect information from respon- 
dents on site comprising Pedestrians, shop and business owners, motorists(public service vehicle users and privately owned vehicle users, motor cyclists),cyclists, wheelchair users, hand cart, pushcarts and wheelbarrow users, and professionals in the urban design and planning field.

The study provided findings from a sample population representative of the target population that is urban dwellers.

The data collected from the sample is representative of urban population not just in Nairobi but across other urban centers in the country and the region at large. This would help contribute to the knowledge on how street layouts affect non-motorized transportation activities in urban centers similar to the study area.

The study's universe was a sample comprised of the shop owners and nonmotorized transport users along Luthuli and Haile Selassie Avenues. The study was interested in determining the physical environment of the street layout and the NMT activities along Luthuli and Haile Selassie Avenues in Nairobi City's CBD. This group potentially included:

1) Non-motorised transport users along the streets under study

2) Shop and stall owners along the streets under study

The sample size for this study was selected from an infinite target population of the study area that comprised of shop owners and non-motorised transport users, along Luthuli and Haile Selassie Avenues who actively use the space.

As the study was a social science research, and no estimate was readily available of the proportion in the target population assumed to have the characteristics of interest, Cochran's formula was used to calculate the sample size (Mugenda \& Mugenda, 2003). For populations that are large, Cochran (1963) developed the equation below to yield a representative sample for proportions

The Cochran formula allowed the study to calculate an ideal sample size given a desired level of precision, desired confidence level and the estimated proportion of the attribute present in the population.

The Cochran formula:

$$
n=\frac{z^{2} p q}{e^{2}}
$$

where:

$n$ is the desired sample size;

$Z$ is the abscissa of the normal curve that cuts off an area $\alpha$ at the tails ( $1-\alpha$ equals the desired confidence level, e.g., 95\%);

$e$ is the desired level of precision (the margin of error);

$p$ is the estimated proportion of an attribute that is present in the population;

$q$ is $1-p$.

Since there was no estimate available of the proportion in the target population assumed to have the characteristics of interest, $50 \%$ was applied as recommended by Fisher et al. (1983).

If the proportion of the target population with the characteristics of interest is 
0.50 , the $z$-statistic is 1.96 , and the research study would desire an accuracy at the 0.05 level, then the sample size would be:

$$
\begin{aligned}
& n=\frac{1.96^{2} \times 0.5 \times(1-0.5)}{(0.05)^{2}} \\
& n=384.16
\end{aligned}
$$

Therefore, the study used a sample size of 384 subjects that were obtained collectively from Luthuli and Haile Selassie Avenues in Nairobi City's CBD.

Out of three hundred and eighty-four (384) respondents that were sampled to take part in the study, three hundred and ten of them filled the tools of data collection. This translates to a study response rate of $81 \%$ that is considered suitable as it surpassed $50 \%$ and therefore the findings of the respondents were used to generalize the targeted population.

\section{Study Area}

\subsection{Background}

Nairobi, the capital of Kenya occupies a land size of about $703.9 \mathrm{~km}^{2}$ (Kenya National Bureau of Statistics, 2020) and has a population of 4,397,073 (Kenya National Bureau of Statistics, 2020). The population of Nairobi is expected to grow, and rapid urbanisation and economic growth provides both opportunities and problems within the urban environment. This has seen congestion soaring and costing the government close to Kshs 1.9 billion every year (Gachanja, 2015).

Nairobi's traffic conditions consist of congestion and roadways that are not safe for its various users. The Nairobi transport system was designed for a population of around 300,000 people, with the natural increase in population and urban migration, the transport system is forced to cater for over 3 million residents (Gonzales, et al., 2009). This has changed over time, as shown by the 2019 population statistics of Nairobi as well as studies around transportation into and within the city.

Figure 5 below shows findings from a recent NMT survey conducted by the Climate and Development Knowledge Network in partnership with the Nairobi Metropolitan Services (NMS) conducted in December 2020 that showcased the growing numbers of NMT users across the busiest walking corridors within the city.

\subsection{Non-Motorized Transport in Nairobi}

Nairobi city is characterized by increasing car ownership and use. As a result, the capital has experienced a surge in congestion and reduced road safety and air quality. The often-unpredictable public transport systems and inconsistent NMT infrastructure means that users are exposed to fast, aggressive, and high motorized traffic volumes. Where NMT facilities are provided, encroachment of these spaces is common. Vulnerable road users such as women and children are regularly forced to walk or cycle in the carriage way. According to the National Transport and Safety Authority, the number of pedestrian fatalities in April 2020 increased by $20 \%$ compared to 2019 (UN-Environment, 2020). 


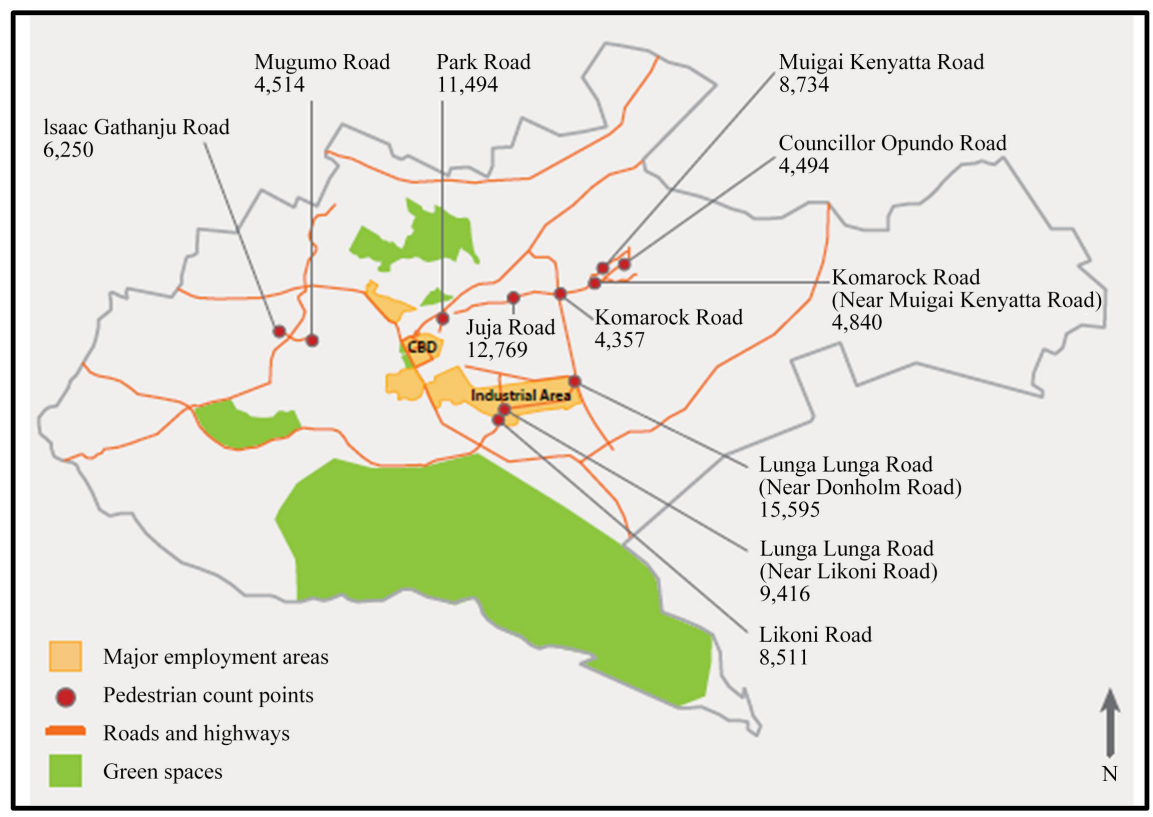

Figure 5. Nairobi's major pedestrian corridors showing number of pedestrians per day. Source: Climate and Development Knowledge Network, February 2021.

Walking accounts for 40 percent of daily trips in Nairobi, and the additional 41 percent of trips by matatu start and end with a walking journey (Salon \& Gulyani, 2019). Despite being the dominant mode of transport in Kenya, NMT receives little emphasis in transport plans and budgets. The majority of road infrastructure funding is channeled towards building roads and expressways to facilitate high-speed movement of private vehicles.

\subsection{Case Study Findings}

Two areas were chosen for evaluation to test the impact of layout of streets on non-motorized transport (NMT) activities in urban areas: Luthuli Avenue and Haile Selassie Avenues Nairobi City's Central Business District (CBD) area were the field research areas.

\subsubsection{Luthuli Avenue}

\section{1) Background to Case Study}

Luthuli Avenue, is part of a larger pedestrian desire-line that runs 700 metres long from River road to Tom Mboya Street and connects to Ambassador hotel then to City Hall way, which links downtown to upper hill and community. It is in proximity of multiple matatu stops and boasts of a retail character.

The Nairobi City County partnered with World Bank to convert the road into a one-way street. The renewal process arose from a feasibility study and was recommended by the United Nations two years ago. Luthuli Avenue was identified together of the foremost congested streets within the city center as ahown in Figure 6, where matatus are parked haphazardly resulting in heavy human and vehicular traffic. 


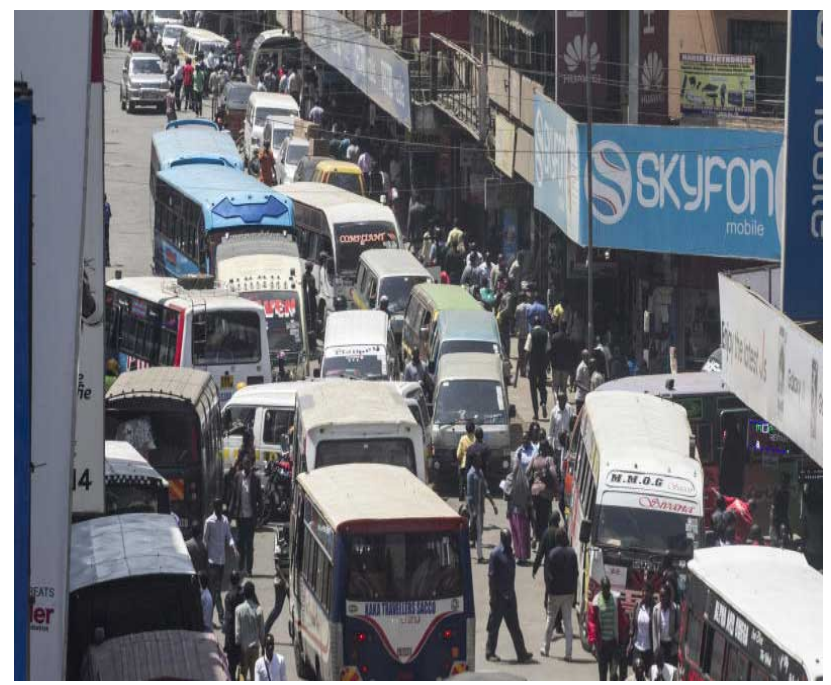

Figure 6. Luthuli Avenue before redevelopment was crowded and congested with both motorised and NMT traffic. Source: https://www.standardmedia.co.ke/nairobi/article/2001334203/revam ped-luthuli-avenue-shakes-off-congested-tag

After the redevelopment the street took on a new look as well as attracted a lot of NMT usres into the space, shown in Figure 7.

2) Condition of Street Layout along Luthuli Avenue

a) Accessibility and Circulation

\section{Access Points}

Luthuli Avenue was observed to have primary access points at the intersection of Tom Mboya Street on one end and the intersection with River Road next to Sagret Hotel. Secondary access points were located along the stretch of the street where various road and lanes meet as observed in Figure 8 below.

\section{Circulation Routes}

Luthuli Avenue was observed to have both motorized and non-motorized transportation, with the former having one one-way street and the latter an expanded pedestrian walkway adjacent a cycling lane separated from the motorised lane through the use of bollards. Adjacent streets and lanes feed into this circulation system as shown in Figure 8. It was recorded that most of the adjacent streets had combined motorised and non-motorised with few demarcated as only non-motorised streets ( $m$ ainly streets).

\section{Conflict Points}

Points of confluence were observed to occur along major access points, and intersections with connecting streets around Luthuli Avenue as shown in Figure 8. Upon further inquiry from various street users along Luthuli Avenue, it was recorded that because of the redevelopment of the street which saw an increase in pedestrians moving through the street space, it also led to an increase in presence of street vendors, hand, and pushcart operators as well as motorbike users who compete for space to conduct their businesses. 


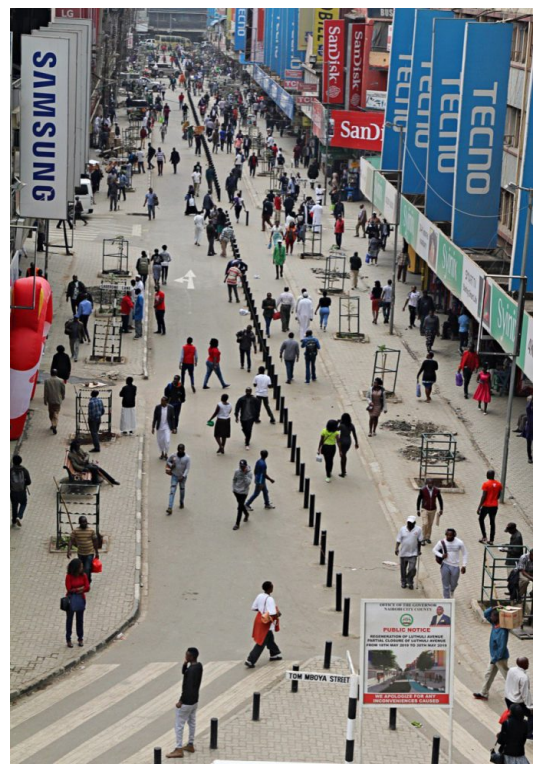

Figure 7. Luthuli Avenue after redevelopment into a one way street with improved NMT transportation. Source: https://www.nation.co.ke, 2019.

\begin{tabular}{c}
\hline ACCESS, CIRCULATION \& CONFLICT ZONES \\
SCALE 1:2500 \\
LEGEND: \\
\hline$\rightarrow$ Main Access Routes $\bigcirc$ Main Entry as well as conflict point \\
\hline Motorised and Non-Motorised transport
\end{tabular}

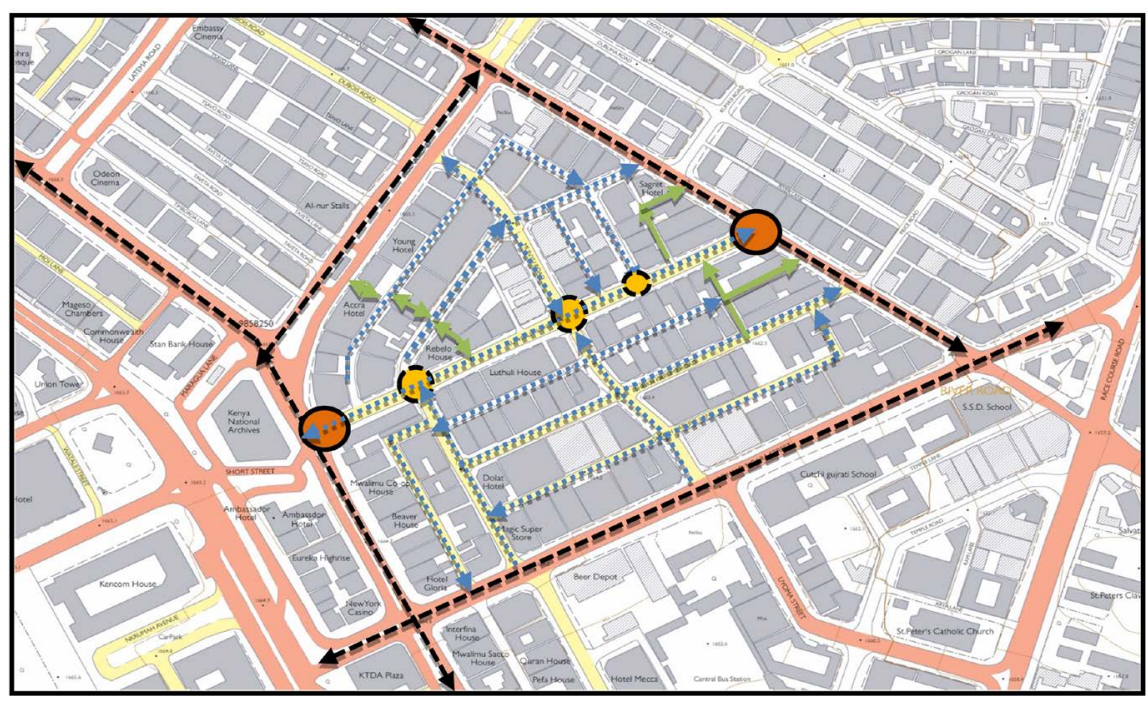

Figure 8. Showing the analysis on access, circulation and conflict zone s along Luthuli Avenue. Source: Author 2021.

\section{b) Physical Infrastructure}

There was presence of a gently sloping pedestrian walkway along the whole 
stretch of Luthuli Avenue, measuring four thousand five hundred millimetres $(4500 \mathrm{~mm})$ in length and one hundred and fifty millimetres $(150 \mathrm{~mm})$ high from the main carriageway and a cycle lane measuring two thousand millimetres $(2000 \mathrm{~mm})$ width and one hundred $(100 \mathrm{~mm})$ millimetres high from the main carriage way with concrete bollards spanning a distance of five hundred millimetres $(500 \mathrm{~mm})$ separating the lane from the main carriageway as shown in Figure 9.

The pedestrian walkway was observed to be relatively flat with concrete paving blocks as a surface finish whereas the cycling lane had smooth tarmac finish. No guide tiles were present along the length of the pedestrian walkway to assist persons with vision impairment.

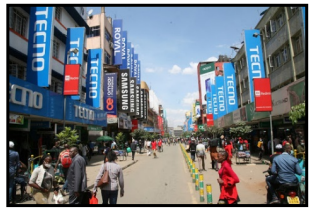

(a)

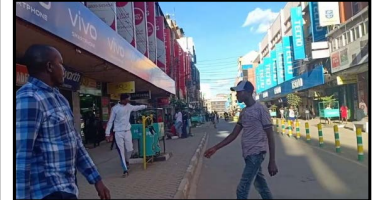

(b)

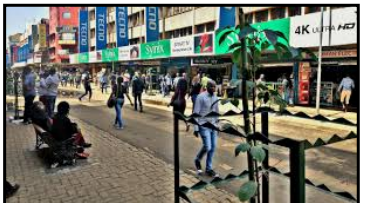

(c)

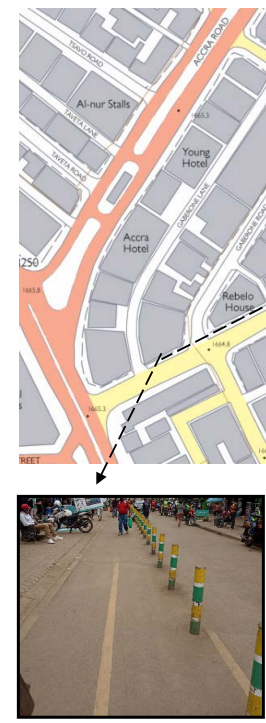

(d)

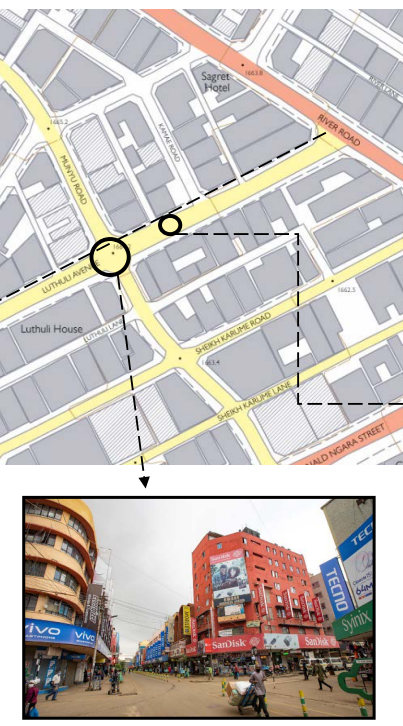

(e)

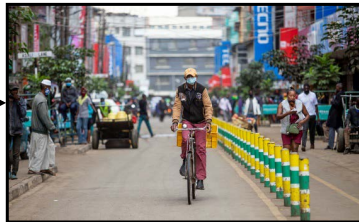

(f)

Figure 9. Showing the general physical condition of Luthuli Avenue. Source: Author, February 2021. (a): Presence of street light boxes that double as advertisement placards are located along the length of Luthuli Avenue. Source: Author, February 2021. (b): Presence of waste metallic waste bins are located along the length of Luthuli Avenue. Source: Author, February 2021. (c): Street furniture present include steel frame wooden benches, concrete slab benches and a timber parklet. Source: Author, February 2021. (d): Presence of demarcated pedestrian walkway and cycle lane along Luthuli Avenue. Source: Author, February 2021. (e): Munyu Road intersection along the Luthuli street with faded zebra crossing markings and no table-top crossing to facilitate slowing down of vehicles as they move through the intersection. Source: Author, February 2021. (f): Poor enforcement of street use resulting into cyclists using the main motorised carriageway and lack of provision for hand carts causing them to invade the pedestrian pathway and motorised road space. Source: Author, 2021. 
There were observed zebra crossing points at the T-junction with Tom Mboya and River Road streets and along Munyu and Mfangano Street intersections points along Luthuli Avenue. It was also observed that there was no table-top crossing facility along mentioned crossing points which had both motorised and non-motorised users. Moreover, it was observed that there were no warning tiles at the edge of the pedestrian walkway to warn NMT users with visual impairment.

There was observed presence of the following street amenities along the length of Luthuli Avenue as shown in Figure 9 below.

1) Street furniture on both edges along the walkways.

2) Waste bins at regular intervals along the walkways.

3) Street timber and concrete benches and parklets.

4) Two bicycle racks adjacent the cycle lane.

5) Three on-street parking slots which were also used as loading bays at select store entrances.

6) No vending spaces along the whole length of the street.

7) No demarcated street space for hand drawn and push carts.

8) No demarcated parking bay for motorcycles.

3) Non-Motorized Transport activities within Luthuli

It was observed presence of both pedestrian and cyclists as majority of the non-motorized transport users along Luthuli Avenue. There was also presence of hand-drawn and pushcart operators along the stretch on the street.

It was recorded that the absence of complete street infrastructure to cater to the different MT (cars and motorcycles) and NMT (pedestrians, cyclist, hand cart and pushcart operators) users led to increased conflict along the street space. This was evidenced by presence of motorcycles parked along the pedestrian pathways and push carts blocking entrances into buildings and access along the street.

Surveys along the street of shop owners revealed that the increase in pedestrians had attracted an increase in informal traders (hawkers) along the street as well as food vendors and shoe cleaners. This further increased the congestion of human traffic along the street. Provision of spaces for vendors ought to be included in the design of streets especially in densified spaces to allow for the service to be available for its intended target audience as well as create a revenue source to the local administration.

The surveys conducted revealed that majority of the road users were comfortable walking through Luthuli Avenue as it was safe for pedestrian use. However, shop owners felt that increased pedestrian use had not improved sales as most of the road users were passers-by and not customers. In their opinion, the pedestrianization project had discouraged retailers from buying goods as they did not have parking facilities to allow them to park their cars and shop along the street. It was noted that none of the buildings along the street had parking facilities within their structures.

Survey respondents were asked to share ideas on how to improve on quality of streets within Nairobi city to make NMT a viable option. These included:

1) The pedestrians' pavements should be expanded since most people without 
cars prefer walking.

2) Additionally, adequate street furniture, in especially seats, should be in designated stages with shades to protect people from sun and rain.

3) Proper drainage designs to prevent surface runoff flooding during rainy seasons.

4) Designated Cycling paths connecting all the streets within CBD to have alternative means of transport.

\subsubsection{Haile Selassie Avenue}

\section{1) Background to Case Study}

Haile Selassie Avenue links the Nairobi Central Business District with a new business district forming in the Upper Hill neighborhood (Gonzales et al., 2009). It has a length of approximately 1.4 kilometers and is abutted by a wide range of economic and recreational activities. Although it has heavy pedestrian traffic, mainly due to a large Matatu bus rank near the Nairobi Railway station and the newly built bus stop across Nairobi Railways Golf Course, there is high competition for space in this economically significant area and pedestrians are continuously severely disadvantaged as a result as evidenced by Figure 10 and Figure 11 below.

\section{2) Condition of Street Layout along Luthuli Avenue}

\section{a) Accessibility and Circulation}

\section{Access Points}

The section of Haile Selassie Avenue under study was observed to be accessible from Uhuru Highway from the southwest edge and Landhies road roundabout from the eastern edge of the CBD. Along its length, the avenue was accessible from Moi Avenue, Tom Mboya Street, Mfangano Street and Racecourse Road intersections. All these were recorded to have both motorised and non-motorised transportation access points as shown in the map below. Majority of these entry points have poorly designed crossings with traffic lights that are inactive, an example is at the Uhuru highway and the railways roundabout. There were also no dedicated cycling crossings present at these entry points.

\section{Circulation Route}

There was recorded presence of both motorised and non-motorised movement along the Haile Selassie Avenue study area. Pedestrian sidewalk was clearly demarcated from the motorised carriage way using change in level, railing and bollards in some sections and live fences in other parts along the section of Haile Selassie Avenue under study. Adjacent streets and lanes feed into this circulation system as shown in Figure 12.

\section{Conflict Points}

Several point of conflict were observed along the section under study of Haile Selassie Avenue as shown in Map X. Majority of them coincided with the main access points into the streets as well as points along the street with dense commercial activities especially near Muthurwa and Wakulima markets as highlighted in Figure 12. 


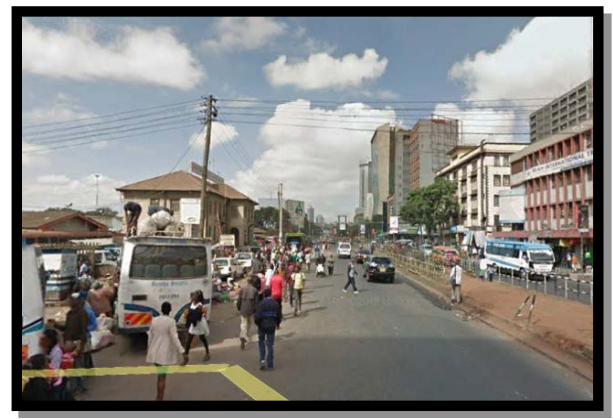

Figure 10. Absence of well-defined NMT infrastructure resulting into conflict of users, resulting into increased NMT accidents. Source: Author using Google Earth pro, 2020.

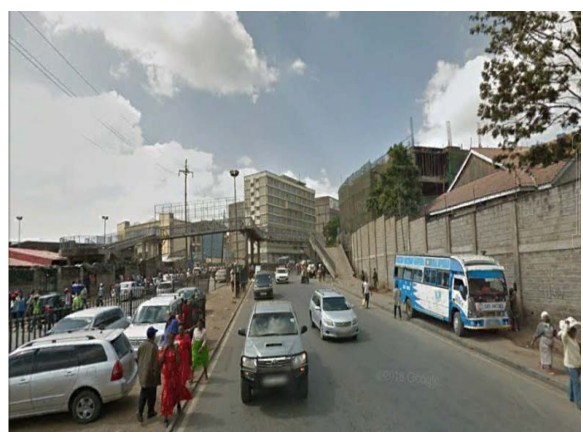

Figure 11. Section of Haile Selassie Avenue showing encroached NMT infrastructure by motorists parking along pedestrian pathways. Source: Author using Google Earth pro, 2020.

ACCESS, CIRCULATION AND CONFLICT ZONES
\[ \underset{\text { Legend }}{\text { Scale 1:2500 }} \]
$\longrightarrow$ NMT and MT
NMT Only

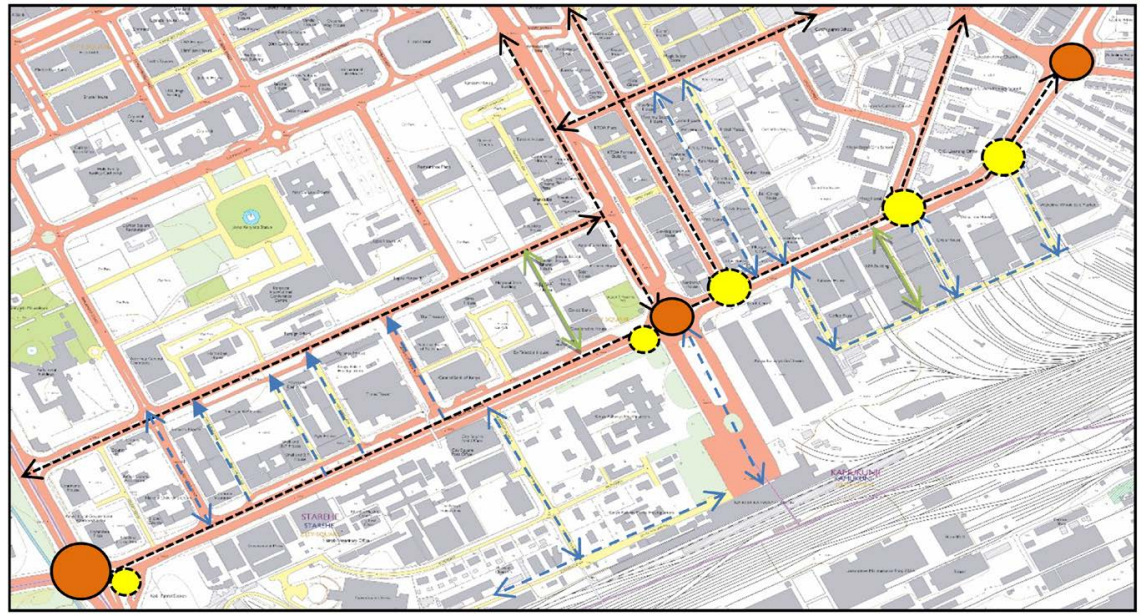

Figure 12. Map Showing the analysis on access, circulation and conflict zones along Haile Selassie Avenue. 


\section{b) Physical Infrastructure}

From the section of Haile Selassie Avenue under study, there was recorded presence of walkways at various widths and heights from the carriageway along the street. The widest recorded width was three thousand millimetres $(3000 \mathrm{~mm})$ at the stretch between AGIP House Bus stop and Telkom House and the narrowest width at one thousand one hundred and fifty millimetres $(1150 \mathrm{~mm})$ at the section of the road towards the Muthurwa Market roundabout. The height from the main carriage way was at one hundred and fifty millimetres $(150 \mathrm{~mm})$. The condition of the walkways varied from one section of the street to another; some section had well maintained sidewalks especially section of Haile Selassie near the Uhuru Highway intersection and the condition worsened as one moved towards Muthurwa market roundabout. It was observed that both these main segments of the street had varying pedestrian traffic volumes, motorized traffic volume, walkway widths and land uses along the street edge. This heavily impacted on the varying condition of the street segments as shown in Figure 13.

There were observed traces of faded zebra crossing markings at the Uhuru Highway roundabout, clear zebra crossing at Railways roundabout with working traffic lights, faded zebra crossing at the intersection with Tom Mboya and Mfangano Streets and at Muthurwa Market roundabout had some traffic lights signalling with faded zebra crossing across Haile Selassie Avenue.

It was noted that majority of both motorised and non-motorised street users did not observe the traffic light signalling at the roundabout crossings where the facilities were present and functional. It was also observed that there were no table-top crossing facilities along mentioned crossing points which had both motorised and non-motorised users.

Moreover, it was observed that there were no warning tiles at the edge of the pedestrian walkway to warn NMT users with visual impairment.

3) Non-Motorized Transport activities within Haile Selassie Avenue

There were observed presence of pedestrians, cyclists and hand drawn cart operators as the majority NMT street users along the section of Haile Selassie Avenue under study. Majority were pedestrians with a few cyclists observed present. This was mainly due to the presence of walkways varying in design along the street. The lack of the well-defined cycling lane as well as bicycle parking infrastructure contributed to the low uptake of cycling along the street.

Surveys from various road users revealed the street had poor NMT infrastructure that led to congestion and unsafe spaces to walk through. Majority only felt safe walking during peak travel times (morning and late afternoon) where there was safety perceived in numbers.

Furthermore, due to the connectivity the street offers from the commercial spaces within the $\mathrm{CBD}$ region to connection to recreation spaces, educational facility (Technical University of Kenya), transportation hubs and public purpose buildings along the street; improved walkway, cycling lanes, defined vendor spaces and transition spaces to link people to the various transportation hubs would greatly increase NMT activities along the space. 


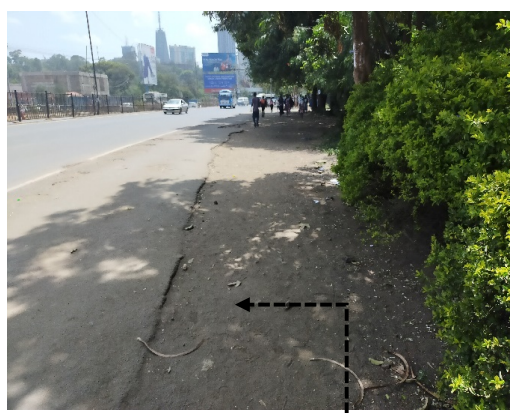

(a)

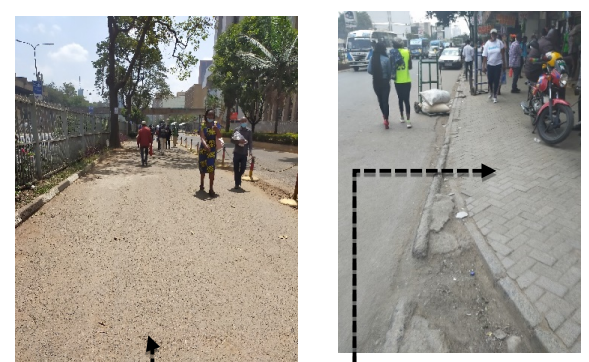

(c)

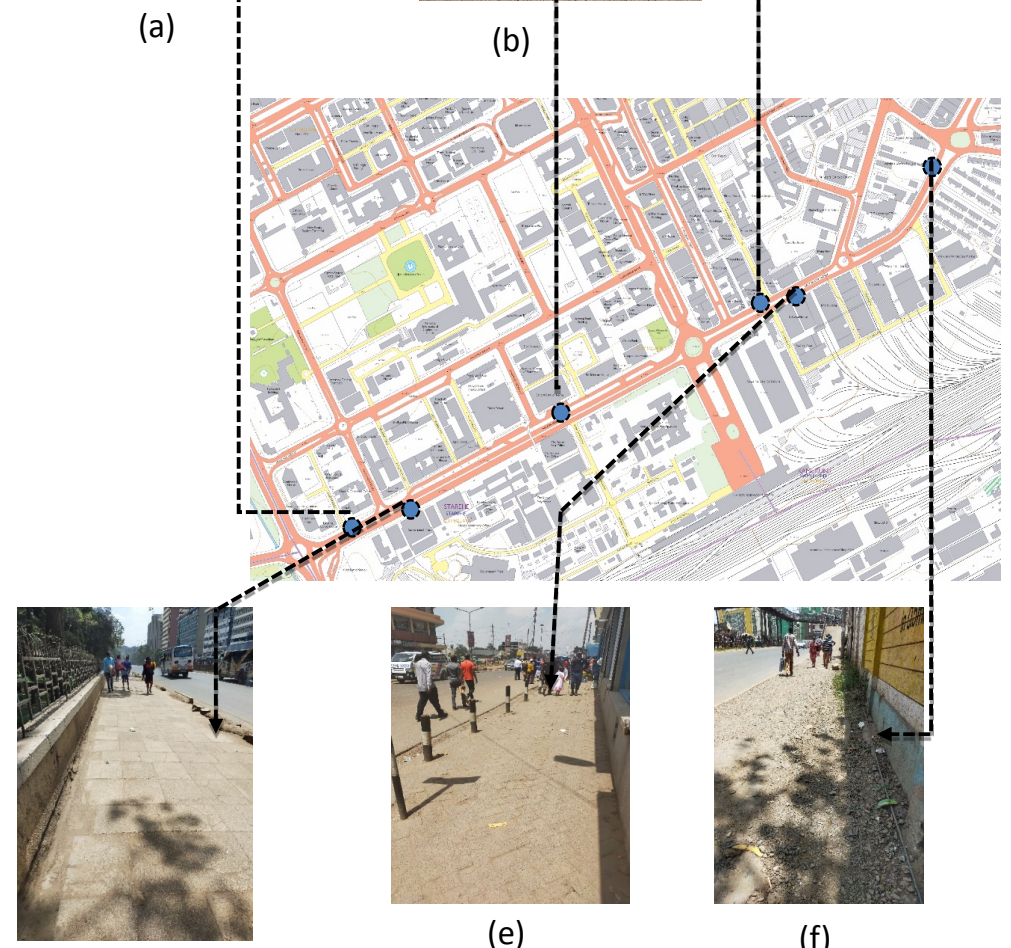

(d)

Figure 13. (a) Section of Haile Selassie Avenue, just off the Uhuru Highway roundabout with loose gravel and uneven tarmac surface finish on the walkway at a width of two thousand millimetres $(2000 \mathrm{~mm})$ from the street edge. Source: Author, February 2021. (b): Section of pedestrian walkway between KRA Hq building and Cooperative Bank house and just off the road carriageway with a loose aggregate $(10 \mathrm{~mm}$ graded crushed aggregate) walkway finish. No provision of cycling lane and the surface offers a level of discomfort as recorded from users alongs the street. Source: Author; February, 2021. (c): Paving blocks surface finish on pedestrian pathway, $1800 \mathrm{~mm}$ wide with several NMT users competing for space along the pathway. Source: Author, February 2021. (d): Section of Haile Selassie street adjacent the Technical University of Kenya with pavement block surface finish, $2000 \mathrm{~mm}$ wide pathway with little sun shading. Source: Author, February, 2021. (e): Section of sidewalk adjacent Kahawa House building. The ground floor space functions as a space of worship. Source: Author, February, 2021. (f): Section of Haile Selassie Avenue near the Landhies Road Roundabout with uneven surface treatment, on $1200 \mathrm{~mm}$ wide pathway that connects to the Muthurwa market footbridge. Source: Author February 2021.

Survey respondents were asked to share ideas on how to improve on quality of streets within Nairobi city to make NMT a viable option. These included: 
1) Protected walkways and cycling lanes dedicated to the various NMT users.

2) Increase street amenities (shaded walkways, greenery, street lights and street furniture) along the street to increase comfort in use.

3) Resolve pedestrian and vehicular "conflict" at the bus stops/stage and roundabout intersections.

4) A designated lane for cycling and hand-drawn carts wide enough to support these on all major streets.

\section{Conclusion}

Most of the presented key urban design principles of successful urban street layouts and how these affect non-motorized transport activities within urban areas, aimed at creating active, interesting, and engaging streetscape which can be recognized significantly along Luthuli Avenue much better than along Haile Selassie Avenue. The major reasons behind the deterioration of Haile Selassie Avenue could be related to the following:

1) Lack of safety measures when designing for NMT users evidenced by unsecured walkways, no dedicated cycling lane, lack of table tops at crossing points discouraged walking and cycling along the street.

2) The building owners and authorities depend on the digital surveillance such as closed-circuit television (CCTV) to secure their stores and streets. And thus they do not seek for the safety of by-passers and pedestrians, resulting in sidewalks that are unengaging with the building frontage and unattractive to NMT users.

3) Inconsistent walkway dimensions (and in some areas, lack of a walkway) and lack of a dedicated cycling path along the full length of the street led to poor linkages with adjacent streets. This reduced the ability of permeability or accessibility by people through that area.

4) Majority of the buildings along the street were allocated for commercial purposes for single and constant use. Furthermore, the building itself also has one function. For instance, a building from the 1st to the 4th or 6th floor serves only commercial purposes or just administrational purposes.

The study recommends the encouragement of multifunctional streets (complete streets) rather than streets serving one form of transportation, vehicular mobility. This can be achieved by increasing the width of the current streets in favor of the sidewalks as an attempt to recreate piecemeal width of streets adapted to density of users. Moreover, creating vendor spaces along the street as part of amenities to serve the street would help reduce conflict currently experienced along Haile Selassie Avenue.

Encourage use of mixed use spaces rather than one function allocated to one building .For example, the allocation of the residential apartments in the upper floors would encourage active building frontage in a bid to increase active surveillance onto the street spaces. In particular, allocation of the residential apartments in the upper floors would encourage active building frontage in a bid to 
increase natural surveillance onto street spaces.

This study may be a guide for the urban designers around the world to take the principles of sustainable urban design into consideration during restructuring of the urban street environment.

\section{Conflicts of Interest}

The authors declare no conflicts of interest regarding the publication of this paper.

\section{References}

Alexander, C., Ishikawa, S., Murray, S., Jacobson, M., Fixdahi, I., \& King Shlomo, A. (1977). A Pattern Language: Towns, Buildings and Constructions. New York, NY: New York Press.

Biggar, M., \& Ardoin, N. M. (2017). Community Context, Human Needs, and Transportation Choices: A View across San Francisco Bay Area Communities. Journal of Transport Geography, 60, 189-199. https://doi.org/10.1016/j.jtrangeo.2017.03.005

Bryceson, D. F., Mbara, T. C., \& Maunder, D. (2003). Livelihoods, Daily Mobility and Poverty in Sub-Saharan Africa. Transport Reviews, 23, 177-196. https://doi.org/10.1080/01441640309891

Cervero, R. (2013). Transport Infrastructure and the Environment: Sustainable Mobility and Urbanism. Paper Prepared for the 2nd Planocosmo International Conference Bandung Institute of Technology, Bandung, Indonesia, 21-22 October 2013.

Cervero, R., \& Duncan, M. (2003). Walking, Bicycling, and Urban Landscapes: Evidence from the San Francisco Bay Area. American Journal of Public Health, 93, 1478-1483. https://doi.org/10.2105/AJPH.93.9.1478

Cervero, R., \& Kockelman, K. (1997) Travel Demand and the 3Ds: Density, Diversity, and Design. Transportation Research Part D: Transport and Environment, 2, 199-219. https://doi.org/10.1016/S1361-9209(97)00009-6

Cochran, W. G. (1963). Sampling Techniques (2nd ed.). New York, NY: John Wiley and Sons, Inc.

Deyoung, R. (1985). Satisfaction from Conservation Activities in North America. Environmental Conservation, 12, 259-260. https://doi.org/10.1017/S0376892900016003

Diaz Olvera, L., Plat, D., \& Pochet, P. (2008). Household Transport Expenditure in Sub-Saharan African Cities: Measurement and Analysis. Journal of Transport Geography, 16, 1-13. https://doi.org/10.1016/j.jtrangeo.2007.04.001

Ewing, R., \& Cervero, R. (2010). Travel and the Built Environment: A Meta-Analysis. Journal of the American Planning Association, 76, 265-294. https://doi.org/10.1080/01944361003766766

Fisher, N. S., Bjerregaard, P., \& Fowler, S. W. (1983). Interactions of Marine Plankton with Transuranic Elements. 1. Biokinetics of Neptunium, Plutonium, Americium, and Californium in Phytoplankton. Limnology and Oceanography, 28, 432-447. https://doi.org/10.4319/lo.1983.28.3.0432

Frank, L. D., \& Engelke, P. O. (2001). The Built Environment and Human Activity Patterns: Exploring the Impacts of Urban Form on Public Health. Journal of Planning Literature, 16, 202-218. https://doi.org/10.1177\%2F08854120122093339

Frank, L., Stone, B., \& Bachman, W. (1999). Linking Land Use with Household Vehicle 
Emissions in the Central Puget Sound: Methodological Framework and Findings. Transportation Research Part D: Transport and Environment, 5, 173-196. https://doi.org/10.1016/S1361-9209(99)00032-2

Gachanja, J. (2015). Mitigating Road Traffic Congestion in the Nairobi Metropolitan Region. Policy Brief No. 2, Nairobi: Kenyan Institute of Public Policy and Research and Analysis.

Gonzales, E. J., Chavis, C., Li, Y., \& Daganzo, C. F. (2009). Multimodal Transport Modeling for Nairobi, Kenya: Insights and Recommendations with an Evidence-Based Model. Berkeley, CA: UC Berkeley Center for Future Urban Transport.

Haq, G., \& Schwela, D. (2013). Transport and Environment in Sub-Saharan Africa. Stockholm: Stockholm Environment Institute.

Heierli, U. (1993). Environmental Limits to Motorisation: Non-Motorised Transport in Developed and Developing Countries. St. Gallen: SKAT.

Herrman, T. (2015). What Is Liveability? Sustainable Cities Initiative. Eugene: University of Oregon.

Hook, W. (2005). Training Course on Non-Motorised Transportation. Eschborn: Deutsche Gesellschaft fur Technische Zusammenarbeit (GTZ).

International Solidarity on Transport and Research in Sub-Saharian Africa (SITRASS) (2004a). Poverty and Urban Mobility in Conakry. Final Report. SSATP No. 09/04/Ckr, Washington DC: World Bank.

https://www.gtkp.com/assets/uploads/20091127-171237-6675-Conakry_en.pdf

International Solidarity on Transport and Research in Sub-Saharian Africa (SITRASS) (2004b). Poverty and Urban Mobility in Douala. Final Report. SSATP No. 09/04/Dla, Washington DC: World Bank.

https://www.gtkp.com/assets/uploads/20091127-171237-6675-Conakry_en.pdf

Kenya National Bureau of Statistics (KNBS) (2020). 2019 Kenya Population and Housing Census: Volume I Population by County and Sub County. Nairobi: Kenya National Bureau of Statistics.

Koska, T., \& Rudolph, F. (2016). The Role of Walking and Cycling in Reducing Congestion: A Portfolio of Measures. FLOW Project, Brussels: European Union. http://www.h2020-flow.eu

Litman, T. (2010). Quantifying the Benefits of Nonmotorized Transportation for Achieving Mobility Management Objectives (Vol. 28). Victoria: Victoria Transport Policy Institute.

Litman, T. (2012). Evaluating Non-Motorized Transportation Benefits and Costs. Victoria: Victoria Transport Policy Institute.

Lucas, K. (2011). Making the Connections between Transport Disadvantage and the Social Exclusion of Low-Income Populations in the Tshwane Region of South Africa. Journal of Transport Geography, 19, 1320-1334. https://doi.org/10.1016/j.jtrangeo.2011.02.007

Martin, A., Goryakin, Y., \& Suhrcke, M. (2014). Does Active Commuting Improve Psychological Wellbeing? Longitudinal Evidence from Eighteen Waves of the British Household Panel Survey. Preventive Medicine, 69, 296-303.

https://doi.org/10.1016/j.ypmed.2014.08.023

Ministry of Environment and Natural Resources (2015). Nationally Determined Contributions Sector Analysis Report. Nairobi , Kenya: Ministry of Environment and Natural Resources.

Montejano, J., Monkkonen, P., Guerra, E., \& Caudillo, C. (2019). The Costs and Benefits 
of Urban Expansion: Evidence from Mexico, 1990-2010. Cambridge, MA: Lincoln Institute of Land Policy.

Montgomery, B., \& Roberts P. (2008). Walk Urban: Demand, Constraints and Measurement of the Urban Pedestrian Environment. Washington DC: The World Bank.

Mugenda, G. A., \& Mugenda, O. G. (2003). Research Methods: Quantitative and Qualitative Approaches. Nairobi: African Centre for Technology Studies.

Mumford, L. (1981). The Highway and the City. Westport, CT: Greenwood Press.

Næss, P. (2015). Built Environment, Causality and Travel. Transport Reviews, 35, 275-291. https://doi.org/10.1080/01441647.2015.1017751

Ndatho, M. (2018). Socio-Economic Effects of Traffic Congestion on Urban Mobility along Jogoo road, Nairobi City County, Kenya. Unpublished Research Report, Nairobi: Kenyatta University.

Postaria, R. (2017). Appraising the Influence of Street Patterns on Non-Motorized Travel Behaviour In Ahmedabad City, India. WIT Transactions on the Built Environment, 176, 527-538.

Ross, A., Rodríguez, A., \& Searle, M. (2017). Associations between the Physical, Sociocultural, and Safety Environments and Active Transportation to School. American Journal of Health Education, 48, 198-209. https://doi.org/10.1080/19325037.2017.1292877

Salon, D., \& Gulyani, S. (2019). Commuting in Urban Kenya: Unpacking Travel Demand in Large and Small Kenyan Cities. Sustainability, 11, Article No. 3823. https://doi.org/10.3390/su11143823

Servaas, M. (2000). The Significance of Non-Motorised Transport for Developing Countries: Strategies for Policy Development. Washington DC: World Bank.

Southworth, M., \& Owens, P. (1993). The Evolving Metropolis: Studies of Community, Neighbourhood, and Street Form at the Urban Edge. Journal of the American Planning Association, 59, 271-287. https://doi.org/10.1080/01944369308975880

Spielberg, F. (1989). The Traditional Neighbourhood Development: How Will Traffic Engineers Respond? Institute of Transportation Engineers (ITE), 59, 17-18.

Sub-Saharan Africa Transport Policy Program (SSATP) (2005). Non-Motorized Transport in African Cities, Lessons from Experience in Kenya, and Tanzania. SSATP Working Paper No. 80, Sub-Saharan Africa Transport Policy Program.

The Climate and Development Knowledge Network (February, 2021). Pedestrianization and Non-Motorized Transport Issue, 1: Users. Nairobi NMT Newsletter, Cape Town: Climate and Development Knowledge Network.

UN-Environment (2020). The Vision of the Nairobi City County Government Is 'To Be a County Where NMT Is the Mode of Choice for Short and Medium Trips'. https://www.unenvironment.org/sw/node/565

United Nations Environment Programme (UNEP) (2009). Share the Road Initiative. https://www.unep.org/urban_environment/NMT_Roads

United Nations Human Settlements Program (UN-HABITAT) (2010). Sustainable Mobility in African Cities. Nairobi: United Nations Human Settlements Program.

United Nations Human Settlements Programs (UN-HABITAT) (2013). Streets as Public Spaces and Drivers of Urban Prosperity. Nairobi: UNON Publishing Services Section.

Vasconcellos, E. A. (2001). Urban Transport, Environment and Equity. The Case for Developing Countries. London: Earthscan.

Victoria Transport Policy Institute (VTPI) (September, 2019). Developing Country 
Transport Demand Management: Transportation Demand Management in Lower-Income Regions. https://www.vtpi.org/tdm/tdm75.htm

Winters, M., Buehler, R., \& Götschi, T. (2017). Policies to Promote Active Travel: Evidence from Reviews of the Literature. Current Environmental Health Reports, 4, 278-285. https://doi.org/10.1007/s40572-017-0148-x 